\title{
THE DESIGN PERFORMANCE OF INTERNAL SPACES AND ITS RELATIONSHIP TO THE SOCIAL VARIABLE: BAGHDAD CAFES ARE A MODEL
}

Wissam Hassan HASHEM"

College of Fine Arts, University of Baghdad, Iraq

\begin{abstract}
Architecture in different eras has accompanied the need and its variables in societies, as social organizations at various levels have led to the emergence of different types of architecture (cities, palaces, temples, homes, service facilities, various recreational facilities to meet these needs, and no era of eras or a community of community facilities is free. For gathering and entertainment differs according to the nature of society, its creed, value and traditions. The emergence of cafes for rest and entertainment came as a natural result of the councils that spread in all rural and urban areas alike, as it was a spacious social space in which communication and learning take place as well as solving social problems, as they were actually schools that did Its positive action in changing the behavior of society and the transfer of its values and traditions, in addition to the fact that the cafes represent the memory of Baghdad, which stores all social changes and political interactions and was the scene of its conflicts, and had an impact on the production of the Baghdadi society over time, and the current research on the first chapter includes the problem of research and the need for it.

Keywords

Design, internal spaces, social variable, Baghdad, cafes.
\end{abstract}

\section{Introduction}

The idea of this research was born out of a problem, which is the answer to the following question: What are the cultural and social factors affecting the design performance of space? The interiors of cafes? While the researcher identified the importance of research with the following: Social research is relegated to the changes that occur to society in general and human behavior in it in the internal space and sheds light on it, as well as to enrich the department with social research and its impact on interior design. From this, the research acquires importance in exposure to internal space. It deviates from its physical capabilities to its influential and influential social impact, and the current research aims to uncover the reality of the designs of traditional and modern Baghdad cafes and their design references, and to find design foundations for Baghdad café spaces in a way that contributes to enhancing the sense of social harmony between these spaces and the privacy of their pioneers, while the current research is objectively defined.

The performance of the internal spaces of the traditional Iraqi cafes compared to contemporary cafes and their relationship to the social variable through the variable of time and place, and spatially: the internal spaces of the cafes of the city of Baghdad, and in time: the cafes operating

* Corresponding author: web.admin@ cofarts.uobaghdad.edu.iq 
in the year 2012 The second chapter includes the research on two topics, the first examines the social performance of Baghdad cafes, while the second researches The design performance of Baghdad cafes, and the research reached results, the most important of which are:

1. Local cafes are the bridge of communication between the past and the present, and they are a vivid memory of architectural evidence and humanitarian activities that I witnessed.

2. The pioneers of local cafes have a moral relationship with the café space, because it represents personal memories for them and fulfills part of their local identity.

3. For the café patrons, the psychological adaptation shows psychological adaptation through the sense of ownership of the place, through the local identity and special symbols that the café reflects.

4. The café-goers adapt physically by taking into account the areas of movement visually and physically in the café space, using the thermal conditioning, which achieves a positive feeling towards the café.

5. The performance of the café is linked to two types of arrangement, one of which is effective through organizing activities inside the café with all its supplements in a traditional way, and the other is influential, which is the liberation from traditionalism and leaving the movement to fit the desires of the cafe-goers.

6. Social change affected all directions, and women became part of the café. Women and mixed cafes appeared, in which women were pioneers, workers and management.

7. The cafes accompanied the technological development and used all the new visual and audio equipment, in addition to that some heritage cafes kept their old equipment to emphasize their authenticity and confirm their local identity

\section{Research Problem:}

Human beings tend to communicate and gather, this need that accompanied man since his inception prompted the formation of gatherings to ensure his safety and the continuity of his life, so it was the first population gathering for hunting and then the agricultural village gatherings, so the society would be in its simplest form, and the population increase and the changing human needs and his requirements developed, to the establishment of population gatherings After that, they became cities and states that embraced him that met the needs of the ever-changing human requirements due to the development of man himself, and his discovery of technologies that increase the pace, effectiveness and interaction of his work, thus becoming more productive culturally and socially.

The evolution of what happened to the overall structures of life and society was accompanied by the decay of needs and the emergence of other needs due to the change of productive systems 
within society itself, or those resulting from communication, dialogue, and cultural crossfertilization between nations in different eras.

Architecture in different eras has accompanied the need and its variables in societies, as social organizations at various levels have led to the emergence of different types of architecture (cities, palaces, temples, homes, service facilities, various entertainment to meet these needs, and no era of eras or a community of societies is devoid of The gathering and recreation facilities vary according to the nature, faith, value and traditions of the community.

The nature of Iraqi society and its historical depth, which over thousands of years produced civilizations that had a great influence in shaping civil life, as it saw the earliest cities and civil gatherings in the Mesopotamian Valley and grew up from them, including social traditions passed down through the generations.

The emergence of cafes for comfort and entertainment came as a natural result of the councils that spread in all rural and urban areas alike. They were a spacious social space in which communication and learning take place as well as solving social problems, as they were indeed schools that did their positive action in changing society's behavior and transmitting its values and traditions. Moreover, the cafes represent the memory of Baghdad, which stores all the social changes and political attractions, was a scene of conflicts, and had the merit in producing the Baghdadi society over time.

The idea of this research was born out of a problem, which is represented by answering the following question: To what extent are the cultural and social factors influencing the design performance of the internal spaces of their spaces?

Baghdad is famous for its two sides - Karkh and Rusafa - for its scientific, cultural and professional councils, where dozens of prominent scholars and notables from among Muslims, Christians and Jews participate in its establishment and management.

Coffee drink This majlis or divan was called a café or coffee, and the general public pronounced it (al-kahwa) and gathered on (al-khawi).

The al-Khafafin café is one of the oldest cafes in Baghdad, or Iraq, at all. According to Sheikh Jalal al-Hanafi, historian of Baghdad, the Khafafin cafe is built With the construction of the Al-Mustansiriya School during the reign of the Abbasid Caliph Al-Mustansir Billah in the year 19. He attributed his name, the Khuffafin, to leather makers from the craftsmen who used to make (slippers) or shoes, in addition to making horse saddles, sword houses and other handicraft leather industries, as these shops surrounded the Al-Mustansiriya School, and it was until recently occupied the same places.

Al-Khafafin Café is linked to the Al-Khafafin Mosque, which dates back to the same date as 
the construction of the Al-Mustansiriya School and the café, where a historical gate leads directly from the café to the mosque, and the café is one of the endowments of the historic mosque. Al-Hanafi said that the artisans from the phaffins used to perform their prayers in the al-Khufafin mosque and then rest at noon in the café.

The location of Baghdad, whose neighborhoods spread on both sides of the Tigris River and the spread of orchards, helped the Baghdadi resort to it, especially in the summer, to prevent the summer heat, so the (sloths) spread on the river's shores in the form of (grads) were special for each group to spend their time in or even sleep in in the summer. In addition to its spread in the carrots spread at the time in the Tigris River in Jadriya now, but the most famous of them were in (Al-Kawiyah) the tourist island of Baghdad.

The first indication of the existence of a café in Baghdad was received in the year (1950 AD). It was called Qahwa (Ghaghal-Zada) at that time, which was built by Sinan Pasha, who was the ruler of Baghdad and its right to a famous Khan and Suq.

Ali al-Wardi describes Baghdad as the largest city in the world in the world in the number of its cafes and bars relative to the number of its population, and the traveler (Taksra) in 1604 mentioned the presence of cafes on both sides of the Tigris and their owners used the Chalgi music to attract customers, while the traveler Bassons 18 drew his attention to many cafes and inquired about their number He was told that it is 300 registered cafes and there are 420 requests to open cafes. In the year 12 the number decreased to 18 as it was mentioned in the records of the state of Baghdad, and returned to increase to 20 cafes, and in 1934 it reached 599 cafes. Since their establishment, the cafes have accompanied all the stages of change in Iraqi society. It was an outlet for the Iraqi individual and a space for cultural and social communication and communication.

\section{Social relations inside the café:}

The café-goers link the mutual relationships with each other on the one hand and between the individual and the café on the other hand, and the active participation in everything that happens inside the space, and the social relationships arising in the café space The process of active participation and interaction depends on social upbringing where the individual and the group learn the various patterns of behavior and trends Regulate the relationships between members of the community through activities in place.

It was impossible to invite friends in their unmarried homes (Zikrit), which contradicts the prevailing traditions, so young people came to the café to communicate with their friends, and they chatted with entertainment games, the most famous of which was the domination and the table, or listening to the storyteller (the storyteller) to attend regularly in the cafes, telling stories 
and news, Café patrons waited patiently, eagerly watched and interacted with novels.

Some cafes were known to the letter, so the people of crafts were present in them to communicate and develop their businesses and trade, while different cafes were used as waiting stations for buses to and from the governorates, and because the movement of buses was slow, which requires a long time, so travelers were waiting in the cafe until the number of passengers was completed, in addition to being a meeting place The people of the province living in Baghdad and communicating with each other, and these cafes were called in the name of garbage cities.

The interaction and communication between café patrons and the interactive atmosphere between them through friendly relations is very important in achieving an effective social environment within the café space, which in turn strengthens its connection with the place. The arrangement of this environment affects the role of interactive social relations among cafégoers by reorganizing the place and seats in a way that facilitates interaction and social communication, as well as increases motivation and desire for excellence

\section{The cafe and the psychological influence:}

The psychological factors of café pioneers and what the café space reflects on them has a great role in its performance inside the space, as it provides them with sufficient opportunities for success in achieving internal compatibility between their various motives and impulses as well as success in external compatibility in their relationship with their surrounding environment, as the surrounding environment is the reason The main reason behind human behavior and when we talk about the environment, we refer to the set of real conditions in which the individual lives and affects him and affects him. The human relationship with the environment in which there is a mutual relationship in two directions not one way, and it is expressed as the feelings that the individual feels within his space through his belonging For this space and the expression of its identity within it, so is the feeling of satisfaction, fun, suspense, excitement, and safety.

Taking care of the physical and psychological environment of the cafe-goers is working to attract and adapt them to the café space, and to move away as much as possible from the tense atmosphere they have through activities within the space between them. Likewise, the ability of the place to express the identity of the individuals who work in it and spend long hours of the day expressing their hobbies and behavior inside this space by feeling his possession of this place and then giving him a personal character by giving him a special identity by using special symbols that express it and help him to belong The place and stay in it and thus affect its performance, as well as the importance of providing a factor of reassurance within the internal 
space of the cafe by providing protection for it from chaos or disturbance, and considering the space an enjoyable place and encourages attendance and communication.

\section{Environmental adaptation of the coffee shop:}

The ability to achieve the goals and the style that is interacted with and leads to the purpose assigned to it by creating an appropriate environment that helps to adapt and comfort within it is the success and suitability of the place is in providing protection from cold or heat and maintaining the requirements of thermal comfort inside, as well as the factor of good ventilation and cleanliness of the place affect The physical and psychological comfort in a space, which helps and motivates him to love staying inside the place with a continuous activity without boredom and boredom, as the process of adaptation of the café user occurs through their interaction with the components of the space as a whole in which they spend special time in what these components contain and the relationships and feelings that affect their performance inside it.

It is important to achieve comfort through attention, as the designer should have the ability to provide the human needs represented by the expressive aspects of the interior space through design treatments to form its formative vocabulary. Which includes the design, psychological, social and environmental characteristics, and one of the most important aspects of the successful performance of the café is the feeling of its patrons of activity, joy, energy and rush within the space, as well as their constant and endearing presence inside the café.

Understanding human behavior in the environment must understand the processes related to it, because through his presence in the environment a person receives its information and then organizes that information according to his goals, so he performs a specific behavioral response and acts in a specific way. The processes related to behavior begin with feeling first, then perception and behavior. Feelings are what motivate the individual to perform a behavior. Then comes the verb that represents the last stage in the mechanics of behavior and appears in an apparent kinematic formula.

\section{Social relations inside the café:}

The café-goers link the mutual relationships with each other on the one hand and between the individual and the café on the other hand, and the active participation in everything that happens inside the space, and the social relationships arising in the café space The process of active participation and interaction depends on social upbringing where the individual and the group learn the various patterns of behavior and trends Regulate the relationships between members of the community through activities in place.

It was impossible to invite friends in their unmarried homes (Zikrit), which contradicts the 
prevailing traditions, so young people came to the café to communicate with their friends, and they chatted with entertainment games, the most famous of which was the domination and the table, or listening to the storyteller (the storyteller) to attend regularly in the cafes, telling stories and news, Café patrons waited patiently, eagerly watched and interacted with novels.

Some cafes were known to the letter, so the people of crafts were present in them to communicate and develop their businesses and trade, while different cafes were used as waiting stations for buses to and from the governorates, and because the movement of buses was slow, which requires a long time, so travelers were waiting in the cafe until the number of passengers was completed, in addition to being a meeting place The people of the province living in Baghdad and communicating with each other, and these cafes were called in the name of garbage cities.

The interaction and communication between café patrons and the interactive atmosphere between them through friendly relations is very important in achieving an effective social environment within the café space, which in turn strengthens its connection with the place. The arrangement of this environment affects the role of interactive social relations among cafégoers by reorganizing the place and seats in a way that facilitates interaction and social communication, as well as increases motivation and desire for excellence

\section{Café functionality:}

Baghdad cafes are among the social clubs that complete the cycle of daily life for the Baghdadi people, and although they are devoid of a special architectural character, they are distinguished by spaces with spacious atmosphere and basic structural characteristics that accommodate numbers of people who seek to rest, amusement and communication, and the functional performance of the café varies during periods of time. About being a place where people come to rest, relax and maintain social relations, the cafe has developed performance in different directions.

Baghdad cafes became famous as cultural clubs and social forums attended by the poets' stalkers, and many of the cafes were named after the Baghdad poets who frequented them. It was the monopoly of the well-to-do, and its presence in the cafe led to attracting customers, the same reason was the cafes the only place in which to attend concerts, especially the Iraqi maqam, and under the influence of this social development, these cafes changed the shape of their construction so that they provided special places for dancing in the café that resemble the stage of the stage called ( With discotheques, some of them actually turned into a nightclub, such as Café Sabaa in the square, whose name turned into Nightclub Saba. 
The cafes were the first nucleus of Iraqi theater, as they displayed Al-Chanu, and the floor and the base that revived the seed of entertaining and satirical comedies, remained (Al-Chanu) for a long time that expresses the concept of (The Food Tiger comic comic) called (Akhbari), which is one of the popular street arts that Moved to cafes and cabarets) It was presented in the evening with the rave as an entertaining carnival for customers, and it was presented daily (in the clubs) as a closing paragraph for its concerts.

Betting cafes have spread, especially in the struggle of roosters and rams, for which periodic matches were held with their patrons, but the matter has evolved in some cafes to become gambling clubs, and in another part of them Al-Jafr has the false games and the celebration of its heroes after each achievement, especially when the old bridge (Dub's Bridge) Whenever he moves from his place. While all these cafes are busy during Ramadan nights with the popular (mhaibis) game.

The most important thing that distinguishes the café space from the rest of the spaces is the presence of "pains" (") pains. It is the vital place. The heritage cafes for the café worker, where he prepares tea and coffee, and contains a set of work consisting of a group of teapots (pots), samuras, stanzanas, and thanksgiving as well as a shelf above the pains. The sugar balls (kaleh bulb) and contains a charcoal protractor and a hot water tank, as well as a wash basin and a gap in one of the icons of the Al-Baghdadi cafe.

The wall of the pains is enveloped from the outside with ceramics decorated with vegetal motifs or shapes that express the café space "like the coffee clutch" or the like. Because of the characteristics of bearing high temperatures and ease.

\section{Results:}

1- Local cafes are the bridge of communication between the past and the present, and they are a vivid memory of architectural evidence and humanitarian activities that I witnessed.

2- The pioneers of local cafes have a moral relationship with the cafe space because of the personal memories it represents for them and realizes their local identity.

3- The intimate relationships between the café-goers themselves and with the coffee shop management provide for social relations and reinforce the prevailing social values.

4- The psychological receptivity of the café-goers is reflected in the extent of their acceptance of the café, including the harmony between their various motives and impulses, and the feeling of satisfaction, pleasure, excitement, excitement and safety.

5- The café demonstrates psychological adaptation through the sense of ownership of the place for the cafe visitors through the local identity and special symbols that the café reflects.

6- Providing the factor of reassurance, safety and non-disturbance is considered a factor 
encouraging attendance and communication.

7- The functional performance of a café is related to the basic needs of comfort, recreation, and the maintenance of human relationships.

8- Since its inception, local cafes have embraced literary circles, and various performing and musical arts such as theater, music and singing, and they were a social and political platform.

9- The local cafes included traditional sports activities such as Al Zourkhana, and it was the headquarters of various sports teams and football is a feature, as well as it contained the arenas of cockfighting and betting. , Providing conditioning.

10- The café-goers adapt physically by taking into account the areas of movement visually and physically in the café's thermal space, which achieve a positive feeling towards the café.

11- The functional performance is achieved through the comfortable physical components provided by the café that meet the desires of the space user.

12- The physical performance is achieved through the physical integrity of the building, the equipment of the internal space of the cafe, the effective and efficient management of the café, and the permanent maintenance.

13- Service performance is shown by the extent of the satisfaction of the cafe visitors with the services and their quality.

14- The performance of the café is linked to two types of arrangement, one of which is effective through organizing activities inside the café with all its supplements in a traditional way, and the other is influential, which is the liberation from traditionalism and leaving the movement to fit the desires of the cafe-goers.

15- Social change affected all directions, and women became part of the café, and women and mixed cafes appeared in which women were pioneers, workers and management.

16- He also used various types of entertainment and drinks in cafes, as well as cooling devices and display designs.

17- The cafes accompanied the technological development and used all the new visual and audio devices, in addition to the fact that some heritage cafes kept their old equipment to emphasize their authenticity and confirm their local identity.

18- Aches are the most prominent focus of performance in local cafes, and it has gone out of performance to become one of the icons of the local cafe.

19- The internal determinants of the café were related to the extent of its technical development, so the prevailing materials and technologies were used in every period of time.

20- Some of these determinants took on a moral character in addition to their physical function, such as rubbing, sediment and oogag with what it contained and the open roof (Sky Light). 


\section{References:}

1- Jassim, Ali Taha, The Effect of Design Characteristics of Natural Light Outlets on the Visual Comfort of Workers in Industrial Buildings, "Master Thesis submitted to the University of Technology, Department of Architectural Engineering, unpublished research, 2009.

2- Jawad, Mustafa and Sousa, Ahmad, planning Baghdad in its various eras, published by the Iraqi Engineers Syndicate, 1949, printed by the Ramzy Foundation for Printing.

3- Al-Hajiya, Aziz Jassim, Baghdadiyat, Picturing the Social Life and Customs of Baghdad during a Hundred Years, Part Three, The Republic of Iraq, Ministry of Culture and Information, Freedom House for Printing, Republic Press, Baghdad, 19.

4- Al-Hajiya, Aziz Jassim, Baghdadiyat, Picturing the Social Life and Habits of Baghdad During a Hundred Years, Part Three, The Iraqi Republic, Ministry of Culture and Information, Freedom House for Printing, Al-Gomhouria Press, Baghdad, 12.

5- Hassan, Dr. Al-Harith Abdul-Hamid, "The Psychological Language in Architecture, Introduction to Architectural Psychology, Pages for Studies and Publishing, Syria, 2009.

6- Abd al-Rasool, Salima, Heritage Buildings in Baghdad, a field study of the Karkh side, Dar al-Kutub Press for Printing and Publishing, Baghdad, 12.

7- Abdul Hadi, Dr. Samer, Organizing the Classroom Environment, Controlling Classroom Behavior, Wael Publishing House, Amman, 2009.

8- Abdul Hadi, d. Samer, Environmental Regulation and Behavior Control, "Wael Publishing House, Amman, 2008.

9- Arar, Dr. Khaled, "Alternatives and Implications for Improving Classroom Quality," Directorate of Education and Science House for Publication, published research.

10- Arar, Dr. Khaled, "Alternatives and Implications for Improving the Quality of Architectural Spaces", Directorate of Education and Science House for Publication, published research.

11- Al-Azzawi, Sadad, Master Thesis of the College of Fine Arts, University of Baghdad.

12- Al-Issawi, Yassin Taha Ismail, Foundations of Interior Design in Heritage Arab Houses of Baghdad, and the possibility of employing the foundations in contemporary interior designs, a master's thesis, College of Fine Arts, Department of Design, University of Baghdad 12.

13- The Folklore Magazine, published by the House of General Cultural Affairs, Ministry of Culture and Information, Issue 6, Sixth Year, 12.

14- Mahdi, Shafiq, Baghdad Cafes, Ministry of Culture for the Baghdad Capital of Arab Culture Project, 2017. Pp. 10-13.

15- Al-Naqshbandi, Zain, (History of the old cafes of Baghdad), Ministry of Culture, the project, Baghdad, Capital of Arab Culture, 2017. 
16- Yusef, Sharif, History of Architecture in Different Ages, Republic of Iraq - Ministry of Culture and Information, Al-Rasheed Publishing House, Baghdad, 12.

17- Yusuf, Nagham Faisal, The Effect of Color Characteristics in Stimulating the Feeling of Belonging to the Interior Space in the Residential Unit, MA Thesis submitted to the University of Technology, Department of Architecture, Unpublished Research, 2000.

18- Ching, francis D.K., "Interior design Van Nastran Reinhold . 1987 , P. 19.

19- Preiser, Wolfgang F.E, "Assessing Building Performance", Elsevier, Butterworth Heinemann, 2005.p85.

20- Kolarekevic, Branco and Malkawi Ali M., "Per formative Architecture, beyond instrumentality"; Spon Press 2005.p205.

21- Chermayeff, Serg, and Christopher Alexander "Community and privacy" Toward new architecture of humanism series, Doubleday and company, Inc., Garden City New York, U.S.A 1963 P. 164.

22- Davidoff, Linda , H. "Introduction to psychology “ Mac Graw-Hill , International Book company U.S.A. 1981 P. 153.

23- Wade, J.W. "Architecture, Problems \& purposes", John Wiley \& Sons, London, 1977, p32.

24- Yaqout Al-DEEB, RESEARCH ON CINEMA AND ITS ROLE IN PRESERVING THE EGYPTIAN FOLKLORE BY APPLYING IT TO SAMPLES OF FILMS, International Journal of Humanities and Language Research, Vol. 2, No. 1, 2019, pp. 5-14.

25- http://iraq.iraq.ir/cpg/albums/Places-Old

26- http://www.ahraraliraq.com/print.php?id=12074

27- http://almfed.com/detail602767.html

28- http://www.alarabiya.net/articles/2012/04/23/209796.html.

Received: July 14, 2019

Accepted: September 20, 2019 